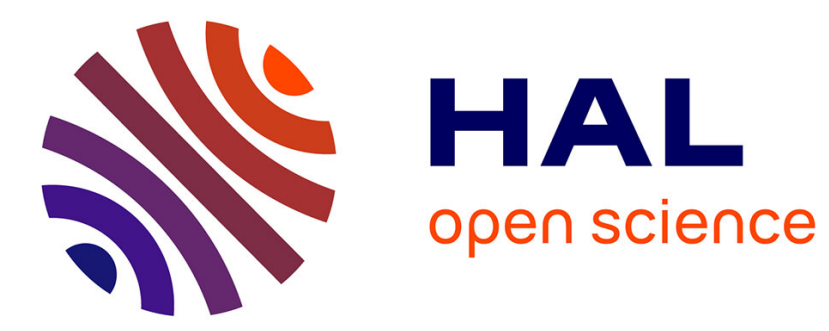

\title{
Vocal fold and ventricular fold vibration in period-doubling phonation: Physiological description and aerodynamic modeling
}

\author{
Lucie Bailly, Nathalie Henrich Bernardoni, Xavier Pelorson
}

\section{- To cite this version:}

Lucie Bailly, Nathalie Henrich Bernardoni, Xavier Pelorson. Vocal fold and ventricular fold vibration in period-doubling phonation: Physiological description and aerodynamic modeling. Journal of the Acoustical Society of America, 2010, 127 (5), pp.3212-3222. 10.1121/1.3365220 . hal-00481069

\author{
HAL Id: hal-00481069 \\ https://hal.science/hal-00481069
}

Submitted on 25 May 2010

HAL is a multi-disciplinary open access archive for the deposit and dissemination of scientific research documents, whether they are published or not. The documents may come from teaching and research institutions in France or abroad, or from public or private research centers.
L'archive ouverte pluridisciplinaire HAL, est destinée au dépôt et à la diffusion de documents scientifiques de niveau recherche, publiés ou non, émanant des établissements d'enseignement et de recherche français ou étrangers, des laboratoires publics ou privés. 


\title{
Vocal fold and ventricular fold vibration in period-doubling phonation: Physiological description and aerodynamic modeling $^{\text {a) }}$
}

\author{
Lucie Bailly, ${ }^{b)}$ Nathalie Henrich, and Xavier Pelorson \\ Département Parole et Cognition, Grenoble Images Parole Signal Automatique (GIPSA-lab), UMR5216 \\ CNRS, Grenoble INP, UJF, Université Stendhal, 961 Rue de la Houille Blanche, Domaine \\ Universitaire, BP 46, 38402 Saint Martin d'Hères Cedex, France
}

(Received 10 July 2009; revised 20 January 2010; accepted 21 January 2010)

\begin{abstract}
Occurrences of period-doubling are found in human phonation, in particular for pathological and some singing phonations such as Sardinian A Tenore Bassu vocal performance. The combined vibration of the vocal folds and the ventricular folds has been observed during the production of such low pitch bass-type sound. The present study aims to characterize the physiological correlates of this acoustical production and to provide a better understanding of the physical interaction between ventricular fold vibration and vocal fold self-sustained oscillation. The vibratory properties of the vocal folds and the ventricular folds during phonation produced by a professional singer are analyzed by means of acoustical and electroglottographic signals and by synchronized glottal images obtained by high-speed cinematography. The periodic variation in glottal cycle duration and the effect of ventricular fold closing on glottal closing time are demonstrated. Using the detected glottal and ventricular areas, the aerodynamic behavior of the laryngeal system is simulated using a simplified physical modeling previously validated in vitro using a larynx replica. An estimate of the ventricular aperture extracted from the in vivo data allows a theoretical prediction of the glottal aperture. The in vivo measurements of the glottal aperture are then compared to the simulated estimations. (C) 2010 Acoustical Society of America. [DOI: 10.1121/1.3365220]
\end{abstract}

PACS number(s): 43.75.Rs, 43.70.Gr, 43.70.Bk, 43.70.Jt [AH] Pages: 3212-3222

\section{INTRODUCTION}

The ventricular folds, also called false vocal folds or ventricular bands, are two laryngeal structures located above the vocal folds, superior to the laryngeal (or Morgagni) ventricle (see Fig. 1). These laryngeal structures are not commonly involved as a vibrating structure during normal phonation. Their physical properties (high viscosity and low stiffness) are different from those of biomechanical oscillators such as the vocal folds (Haji et al., 1992). Yet, their vibration has been observed during specific vocal gestures: Asian throat singing (Fuks et al., 1998; Lindestad et al., 2001; Sakakibara et al., 2001, 2004), Mediterranean traditional polyphony (Henrich et al., 2006), rock singing (Zangger Borch et al., 2004), pathological phonation (Lindestad et al., 2004; Nasri et al., 1996; Von Doersten et al., 1992). Several vibratory gestures can be distinguished: periodic or aperiodic, in phase or not with the vocal fold vibration, with or without ventricular contact. In this study, we focus on a particular type of ventricular fold vibratory movement, referred to as vocal-ventricular phonation mode by Fuks et al. (1998). In this phonatory gesture, the ventricular fold vibratory movement is periodic, occurring every two glottal cycles, in antiphase with the glottal vibration (Fuks et al., 1998; Lindestad et al., 2001; Sakakibara et al., 2001, 2002,

\footnotetext{
a) This paper is based partially on a talk presented at the 6th ICVPB, Tampere, Finland, 6-9 August 2008.

${ }^{b}$ Present address: Laboratoire Sols Solides Structures Risques (3S-R), Domaine Universitaire, BP53, 38041 Grenoble Cedex 9, France.
}

2004; Henrich et al., 2006). It goes with a period-doubling phenomenon, i.e., a perceived octave jump below the original tone.

The physiological and physical nature of this complex laryngeal vibratory gesture is poorly understood. As both the vocal folds and ventricular folds are vibrating, is there any physical interaction between these two laryngeal structures? If so, what is the nature of this interaction? In light of recent studies, it seems interesting to explore the hypothesis of a possible aerodynamic interaction. Previous experimental investigations dealing with in vitro set-ups have provided an initial insight into the influence of a supra-glottal constriction on the glottal airflow (Shadle et al., 1991; Pelorson et al., 1995; Agarwal, 2004; Kucinschi et al., 2006; Finnegan and Alipour, 2009; Bailly et al., 2008; Bailly, 2009). Using a rigid non-oscillating replica combining vocal folds and ventricular folds, Agarwal (2004) observed an influence of the laryngeal geometry on the translaryngeal airflow resistance. An increase in translaryngeal airflow resistance has also been evidenced on excised canine larynges by Alipour et al. (2007) and using the same experimental set-up, a median or antero-posterior ventricular compression has resulted in a mean subglottal-pressure increase and an airflow decrease (Finnegan and Alipour, 2009). Experiments made on in vitro static replicas have shown that the presence of a supra-glottal constriction results in a decreased glottal-jet curvature (Shadle et al., 1991; Kucinschi et al., 2006), and a downstream shift of the position of glottal separation point, inducing a conservation of the flow laminar properties over a 


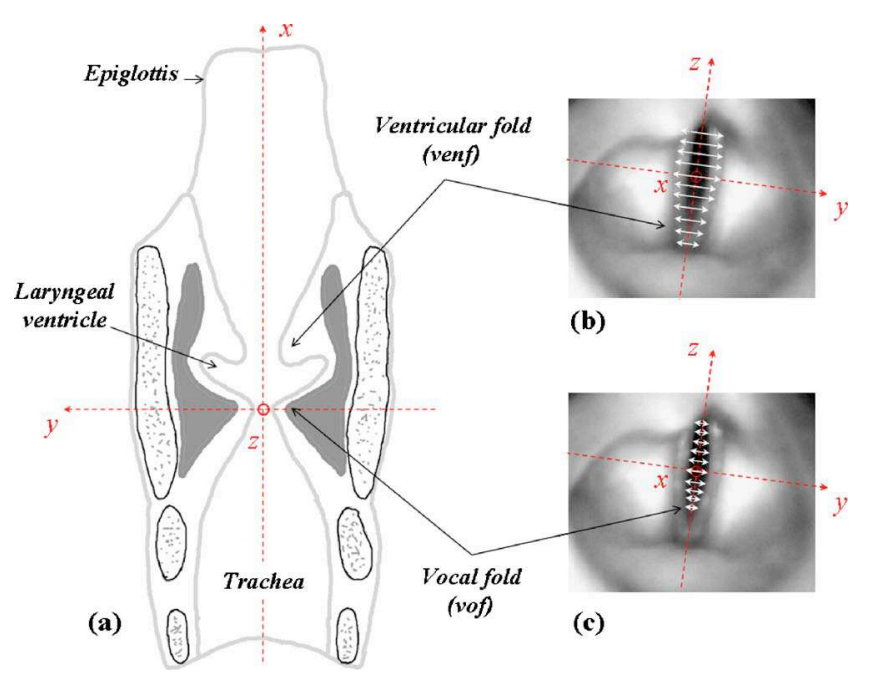

FIG. 1. (Color online) (a) Rear view coronal section of the larynx, (b) [resp. (c)] description of the minimal aperture width at the constriction between the ventricular folds, $\tilde{h}_{\mathrm{venf}}(z, t)$ [resp. the vocal folds, $\left.\tilde{h}_{\mathrm{vof}}(z, t)\right]$ on a frontal view of the human larynx during phonation (in vivo high-speed recordings; venf: ventricular fold; vof: vocal fold).

longer distance (Kucinschi et al., 2006). A significant pressure recovery associated with a reattachment of the jet-flow to the constriction has been observed in Pelorson et al. (1995) and also measured and theoretically predicted in Bailly et al. (2008). The geometry of the constriction affects the phonation threshold pressure and fundamental frequency of a self-oscillating vocal fold replica (Bailly et al., 2008; Bailly, 2009). In complement to these in vitro observations, explorations of throat singing have shown that ventricular fold closure coincides with a decrease in glottal-flow amplitude every two glottal cycles (Fuks et al., 1998; Lindestad et al., 2001). Higher oesophageal pressures have been measured by Fuks et al. (1998) during a switch from modal phonation to vocal-ventricular mode.

This study explores the physiological correlates of vocal-ventricular periodic vibrations, and the aerodynamic impact of ventricular vibration on the vocal fold selfsustained oscillation. The vocal gesture of a professional singer is analyzed by the use of high-speed cinematography combined with acoustic and electroglottographic (EGG) recordings, detailed in Part II (II A and II B). A simplified physical modeling of phonation is presented in Sec. II C, which was previously validated in vitro using a vocal fold/ ventricular fold replica. Part III provides a quantitative physiological description of the co-oscillations, deduced from the detection of glottal and ventricular areas, the kymographic processing of the laryngeal images and the analysis of EGG signals (Sec. III A). The glottal aperture and laryngeal pressure distribution are theoretically predicted from the measured ventricular area as a function of the subglottalpressure (Sec. III B).

\section{MATERIAL AND METHOD}

In the followings, if $X$ is a function of time $\mathrm{t}, X_{n}$ refers to the corresponding normalized quantity, such as: $X_{n}$

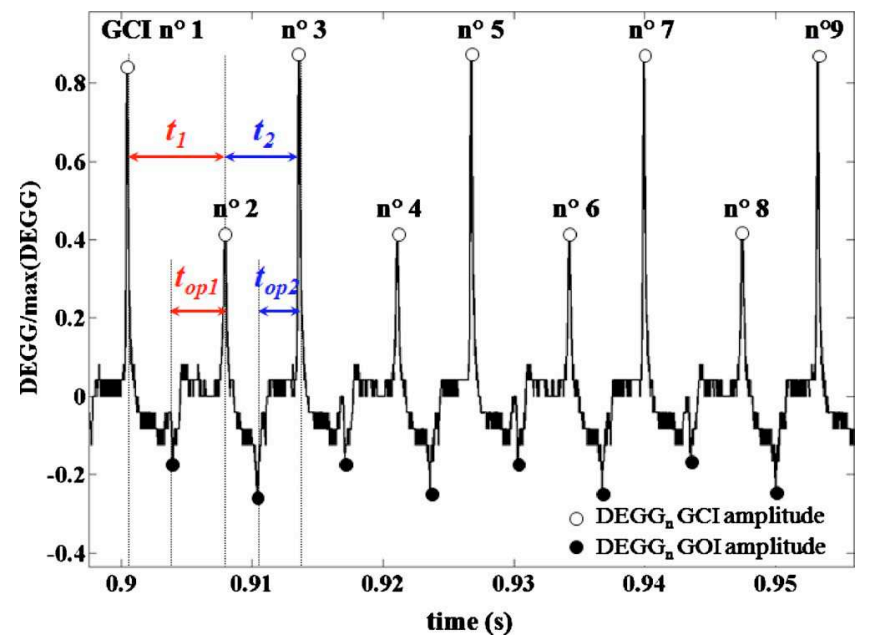

FIG. 2. (Color online) A typical example of eight-period normalized DEGG $\left(\mathrm{DEGG}_{n}\right)$ signal, extracted from the database during the specific growly phonation and processed with a peak detection method (GCI: glottal closing instants; GOI: glottal opening instants).

$=X / \max _{t}(X)$. Each geometrical variable $X$ introduced in the theoretical description refers to a real quantity measurable at human scale, noted $\tilde{X}$.

\section{A. Data recordings}

The experiment was conducted at the University Medical Center Hamburg-Eppendorf in the Department of Voice, Speech and Hearing Disorders. A professional male singer (MW, age 41) was recorded while performing different phonations, among which two particular utterances are selected and compared within the scope of this study: a case of normal phonation, and an example of specific growly phonation, perceptually similar to Asian throat singing. This latter case is characterized by vocal-ventricular periodic vibrations.

High-speed cinematographic recordings of the laryngeal movement were made by inserting a rigid endoscope into the oral cavity (Wolf $90^{\circ} \mathrm{E}$ 60491) with a continuous light source (Wolf 5131) and a digital black-and-white CCD camera (Richard WOLF, HS-Endocam 5560). The recording sequence duration was approximately $4 \mathrm{~s}$, with a camera frame rate of 2000 frames/s and an image resolution of 256 $\times 256$ pixels. Audio signal was recorded simultaneously with a microphone placed at the end of the endoscope (Wolf 5052.801). The electroglottographic signal was recorded simultaneously with a dual-channel electroglottograph [EG2, Rothenberg (1992)]; two electrodes were placed either side of the larynx.

\section{B. Data processing}

\section{EGG signal processing}

Glottal closing instants (GCIs) and glottal opening instants (GOIs) are detected on the time derivative of the EGG signal (DEGG), using a threshold-based peak detection method (Henrich, 2001; Henrich et al., 2004). As illustrated in Fig. 2, the GCI peaks are numbered in order of appearance, a parameter, which completes time and amplitude information for each peak. A distinction is made between the 


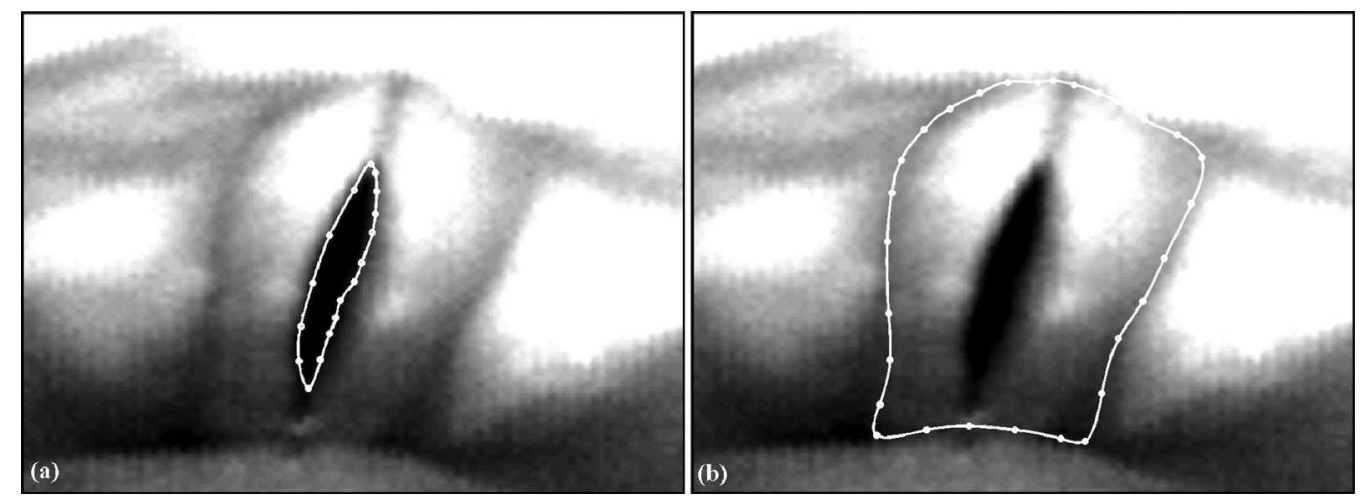

FIG. 3. Illustration of a typical high-speed laryngeal image and the detected contours of the glottal (a) and ventricular fold aperture (b) areas.

two cycles inside a sequence of two glottal cycles. The duration of each glottal cycle (resp. $t_{1}$ and $t_{2}$ ) is calculated as the duration between two successive GCIs (resp. odd-even GCIs and even-odd GCIs). Glottal open time (resp. $t_{\mathrm{op} 1}$ and $\left.t_{\mathrm{op} 2}\right)$ is measured as the duration between a GOI and the following GCI. Open quotient $\left(O_{q}\right)$ is calculated as the ratio between glottal open time and cycle duration.

\section{High-speed image processing}

a. Glottal and ventricular aperture area extraction. Using the MATLAB Image Processing Toolbox, high-speed images are resized to focus on the area of interest. They are smoothed using a bicubic scaling filter (radius 4). Glottal and ventricular contours are manually detected by shaping Bezier curves on each high-speed image, following an algorithm described in Serrurier and Badin (2008) (see Fig. 3). The glottal and ventricular space areas $\left(\widetilde{A}_{\text {vof }}\right.$ and $\left.\widetilde{A}_{\text {venf }}\right)$ are computed from the detected contours by generic surface triangular meshes (Serrurier and Badin, 2008). For each selected time sequence, the detected areas $\widetilde{A}_{\text {vof }}(t)$ and $\widetilde{A}_{\text {venf }}(t)$ are normalized by their maximum values, and resampled to the sampling frequency of the synchronized EGG and DEGG signals $(44170 \mathrm{~Hz})$ with cubic interpolation. Therefore, the measured parameters are $\widetilde{A}_{\text {vof }_{n}}(t)$ and $\widetilde{A}_{\text {venf }_{n}}(t)$.

During the growly phonation, the investigated phonatory gesture includes a narrowing of the supraglottic airway. This laryngeal configuration makes it difficult to detect the effective values of ventricular fold aperture and glottal areas. In such a case, both areas $\widetilde{A}_{\text {vof }}$ and $\widetilde{A}_{\text {venf }}$ are obviously underestimated. Nevertheless, the aryepiglottic constriction beyond the ventricular folds does not vary much during the sequence. Therefore, we can assume that the method provides a good estimate of the dynamical evolution of the measured areas.

Due to the demanding video-laryngoscopic procedure, magnitudes of recorded vocal and ventricular motions have not been calibrated. As an alternative, we chose to graduate their values with the physiological data available in the literature (Hollien and Colton, 1969; Wilson, 1976; Kitzing and Sonesson, 1967; Hirano et al., 1983; Agarwal et al., 2003; Agarwal, 2004). Assuming that $\widetilde{h}_{\mathrm{vof}}(z, t)$ and $\tilde{h}_{\mathrm{venf}}(z, t)$ represent the opening width observed at the constriction between the vocal and the ventricular folds respectively (see
Fig. 1), the maximal glottal and ventricular metric magnitudes observed during the phonatory gesture are imposed in accordance with the bibliographical study $\left(\widetilde{h}_{\mathrm{vof}_{\text {ref }}}\right.$ and $\left.\tilde{h}_{\text {venf }}{ }_{\text {ref }}\right)$ and defined as follows:

$$
\begin{aligned}
& \tilde{h}_{\mathrm{vof}_{\mathrm{ref}}}=\max _{t, z}\left(\widetilde{h}_{\mathrm{vof}}(z, t)\right)=1 \mathrm{~mm} \\
& \tilde{h}_{\mathrm{venf}_{\mathrm{ref}}}=\max _{t, z}\left(\widetilde{h}_{\mathrm{venf}}(z, t)\right)=2.5 \mathrm{~mm} .
\end{aligned}
$$

Note that in Eq. (1), the ventricular magnitude $\tilde{h}_{\text {venf }}$ ief is arbitrarily adjusted smaller than the mean value measured in previous physiological studies during normal phonation [around 5mm in Agarwal et al. (2003) and Agarwal (2004) for instance], in order to account for the initial ventricular constriction observed to switch into the specific studied growly phonation.

The depth of the section along the $z$ direction, noted $W$, is assumed identical and $x$-invariant across the vocal fold and the ventricular fold constrictions. Similarly, its value is chosen in agreement with physiological studies mentioned above $(W=15 \mathrm{~mm})$. Two calibration factors are defined such as:

$$
C_{\mathrm{vof}}=\tilde{h}_{\mathrm{vof}_{\mathrm{ref}}} \cdot W \text { and } C_{\mathrm{venf}}=\tilde{h}_{\mathrm{venf}_{\mathrm{ref}}} \cdot W .
$$

Two additional geometrical parameters, the glottal and ventricular mean apertures measured along the $z$ direction, are deduced from the detected areas $\widetilde{A}_{\text {vof }_{n}}(t)$ and $\widetilde{A}_{\text {venf }_{n}}(t)$. Those are defined under the approximation of a rectangular mean section area at the glottal and ventricular levels, such as:

$$
\begin{aligned}
& \left\langle\tilde{h}_{\mathrm{vof}}\right\rangle(t)=C_{\mathrm{vof}} \cdot \tilde{A}_{\mathrm{vof}_{n}}(t) / W \\
& \left\langle\tilde{h}_{\mathrm{venf}}\right\rangle(t)=C_{\mathrm{venf}} \cdot \widetilde{A}_{\mathrm{venf}_{n}}(t) / W .
\end{aligned}
$$

In the end, the conversion of the measured areas $\widetilde{A}_{\text {vof }}(t)$ and $\widetilde{A}_{\text {venf }}(t)$ from pixels into $m^{2}$ is achieved under the approximation:

$$
\begin{aligned}
& \tilde{A}_{\text {vof }}(t)=C_{\text {vof }} \cdot \tilde{A}_{\mathrm{vof}_{n}}(t)=\left\langle\tilde{h}_{\mathrm{vof}}\right\rangle(t) \cdot W \\
& \tilde{A}_{\text {venf }}(t)=C_{\text {venf }} \cdot \tilde{A}_{\mathrm{venf}_{n}}(t)=\left\langle\tilde{h}_{\mathrm{venf}}\right\rangle(t) \cdot W .
\end{aligned}
$$

Note that the perspective effect occurring within the visual field of the camera yields to the underestimation of the ratio 


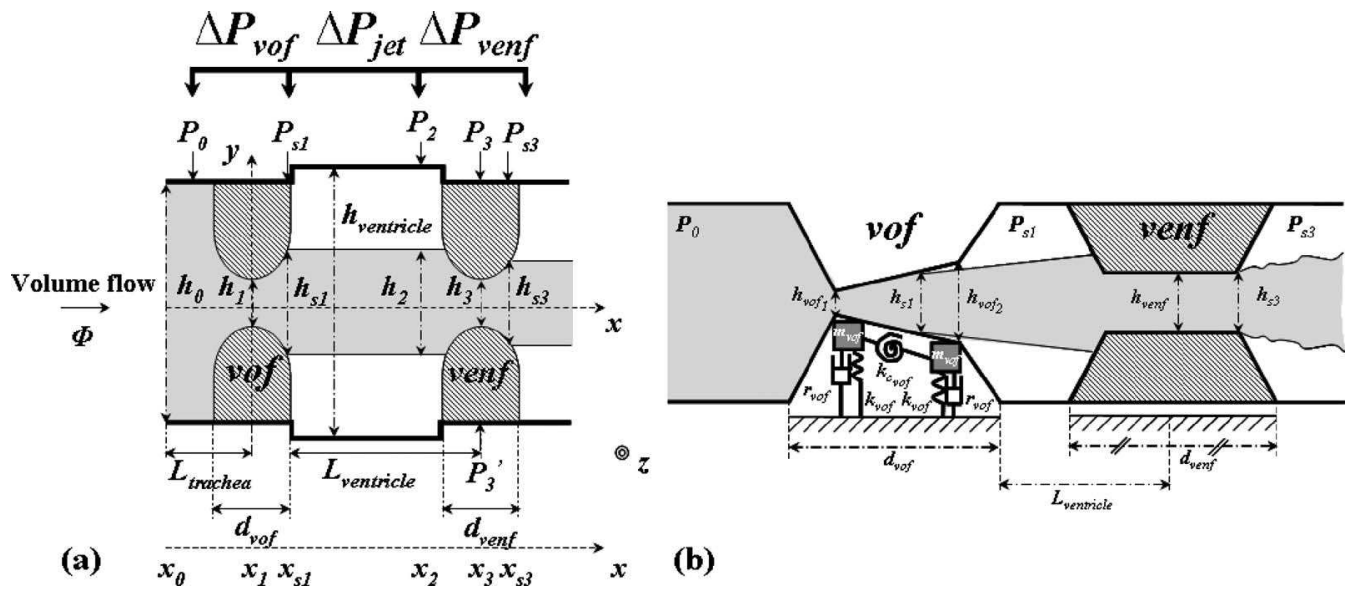

FIG. 4. (a) Geometrical sketch of the larynx and relevant quantities of the aerodynamic study. (b) Sketch of the two-mass model of the vocal folds (M2M) combined with the theoretical flow description of the ventricular fold influence and the ventricular geometry used in this study. $P_{s_{3}}=0$.

$\left\langle\tilde{h}_{\mathrm{venf}}\right\rangle /\left\langle\tilde{h}_{\mathrm{vof}}\right\rangle$, as compared to the physiological reality. Yet, this optical phenomenon is left aside from the high-speed image processing, because the axial width of the larynx (along the $x$ direction) cannot be graphically measured, and because the discrepancy thus committed is negligible to a first approximation (Bailly, 2009).

b. Kymographic analysis. High-speed images are also analyzed by means of a kymographic method inspired from Švec and Schutte, 1996. It consists of a visualization method for high-speed investigation of laryngeal vibrations. A line is selected on the image, perpendicular to the median glottal axis. This line is plotted as a function of time, along with the synchronized EGG and DEGG signals. This method does not allow for visualization of glottal vibrations along the whole glottal length, but it provides a detailed representation of the vocal dynamics at the selected position on the glottis.

\section{Theoretical modeling}

First, a simplified theoretical description of the laryngeal airflow dynamics is proposed. Then, corresponding aerodynamic forces are combined with mechanical forces related to a two-mass model of the vocal folds.

\section{Flow theory through the larynx}

The basic aerodynamic impact implied by the presence of the ventricular folds in the larynx on the pressure distribution and the vocal fold self-oscillations is extensively described in Bailly et al., 2008 and Bailly, 2009. A schematic representation of the laryngeal geometry considered in this investigation is given in Fig. 4 along with all relevant parameters of the aerodynamic study.

The larynx is assumed to be symmetric with respect to the $x$ and $z$ axes. In the following, indices $i$ correspond to specific positions along the $x$ axis, as indicated in the figure. $h_{i}=h_{i}\left(x_{i}, t\right)$ refers to the height of the channel flow at the position $x_{i}$. The parameters $h_{\mathrm{vof}}$ (resp. $\left.h_{\mathrm{venf}}, h_{\mathrm{ventricle}}\right)$ corresponds to the minimal aperture of the vocal folds (resp. the ventricular folds, the ventricle). Note that in this study, $h_{\mathrm{vof}}$ always equals $h_{1}$, whereas $h_{\text {venf }}$ may differ from $h_{3}$, for specific geometric laryngeal configurations where the glottal jet- flow does not interact with the ventricular bands and detaches from the ventricular walls (Bailly, 2009). $A_{\mathrm{vof}}$ (resp. $A_{\text {venf }}$ ) refers to the glottal area (resp. the ventricular area) in the axial plane $x_{1}=$ constant (resp. $x_{3}=$ constant). In our theoretical approximation, these areas are rectangular: $A_{\mathrm{vof}}=W$ $\times h_{\text {vof }}$ and $A_{\text {venf }}=W \times h_{\text {venf. }} P_{i}=P_{i}\left(x_{i}, t\right)$ represents the relative pressure predicted at $x_{i}$, as compared to the ambient atmospheric pressure.

Three coupled subsystems are considered for modeling the airflow dynamics through the larynx:

- the pressure drop across the glottis: $\Delta P_{\mathrm{vof}}=P_{0}-P_{s 1}$;

- the emerging jet evolving in the ventricle, with a dissipation of kinetic energy: $\Delta P_{\text {jet }}=P_{s 1}-P_{2}$;

- the pressure drop across the ventricular folds: $\Delta P_{\text {venf }}=P_{2}$ $-P_{s 3}$.

All theoretical aspects used in the followings directly refer to this simplified model of phonation, applied under the assumptions of a semi-empirical Liljencrant's flow separation model, a "turbulent" jet-flow geometrical expansion in the ventricle, dissipation $\Delta P_{\text {jet }}$ being neglected, and a quasisteady Bernoulli flow dynamics description [see Bailly et al. (2008) and Bailly (2009) for more details].

\section{Simulation of the vocal fold dynamics in interaction with the ventricular fold constriction}

A distributed two-mass model (M2M) combining mechanical and airflow theoretical descriptions is used to simulate the glottal behavior in time, through the predictions of the mass apertures $h_{\mathrm{vof} 1}(t)$ and $h_{\mathrm{vof} 2}(t)$, as illustrated in Fig. 4. For the sake of simplicity, the acoustical propagation in the resonators downstream to the glottal source is not implemented in this study.

a. Geometrical parameters. For all simulations discussed below, we chose a laryngeal configuration consistent with physiological measurements (Hollien and Colton, 1969; Wilson, 1976; Kitzing and Sonesson, 1967; Hirano et al., 1983; Agarwal et al., 2003; Agarwal, 2004): 


$$
\begin{aligned}
& h_{0}=20 \mathrm{~mm}, d_{\text {vof }}=4 \mathrm{~mm}, h_{\text {ventricle }}=23 \mathrm{~mm} \text {, } \\
& L_{\text {ventricle }}=4.7 \mathrm{~mm}, d_{\text {venf }}=5.5 \mathrm{~mm} .
\end{aligned}
$$

The following two input values of the ventricular aperture $h_{\text {venf }}(t)$ are imposed, depending on the phonation investigated.

- $h_{\mathrm{venf}}(t)=h_{\mathrm{ventricle}}$ is considered for the study of normal phonation with no implication of the ventricular folds in the phonatory gesture.

- $h_{\mathrm{venf}}(t)=\left\langle\tilde{h}_{\mathrm{venf}}\right\rangle(t)[$ see Eq. (3)] is considered in the case of vocal-ventricular periodic vibrations.

The initial glottal aperture $h_{\text {vof }}(t=0)=\min \left(h_{\text {vof }_{1}}(t\right.$ $\left.=0), h_{\mathrm{vof}_{2}}(t=0)\right)$ is fixed to $0.2 \mathrm{~mm}$, so that the two-mass model could simulate stable self-sustained glottal oscillations with complete closure of the vocal folds in the absence of ventricular folds [for $h_{\mathrm{venf}}(t)=h_{\text {ventricle }}$.

b. Mechanical model The applied reduced mechanical model is a variation in the symmetrical two-mass model proposed by Lous et al. (1998), and further detailed in Ruty (2007) and Ruty et al. (2007). It is controlled by a set of mechanical parameters: the mass $\left(m_{\mathrm{vof}}\right)$, spring stiffness $\left(k_{\mathrm{vof}}, k_{c_{\mathrm{vof}}}\right)$ and damping $\left(r_{\mathrm{vof}}\right)$.

In the following, the simulated sequences correspond to four ventricular cycles selected during vocal-ventricular periodic vibrations. The value of $m_{\mathrm{vof}}$ is chosen in agreement with previous studies on voice modeling using a two-mass model of the vocal folds (Miller et al., 1988; Vilain, 2002; Ruty, 2007). The stiffness $\left(k_{\mathrm{vof}}\right)$ and damping $\left(r_{\mathrm{vof}}\right)$ input parameters are fitted so that the frequency of two consecutive glottal cycles $1 /\left(t_{1}+t_{2}\right)$ is identical to the measured one (mean value of $75 \mathrm{~Hz}$ ) with a relative error below $1 \%$, when the ventricular folds are vibrating. The coupling constant $k_{c_{\text {vo }}}$ is arbitrarily set equal to $0.5 . k_{\mathrm{vof}}$. The mechanical parameters are thus summarized below:

$$
\begin{aligned}
& m_{\mathrm{vof}}=0.05 \mathrm{~g}, \quad k_{\mathrm{vof}}=42.65 \mathrm{~N} \mathrm{~m}^{-1}, \\
& r_{\mathrm{vof}}=10^{-3} \mathrm{~N} \mathrm{~s} \mathrm{~m}^{-1} .
\end{aligned}
$$

c. Airflow model. The laryngeal airflow is simulated as previously described, with viscous losses considered in addition along the glottal channel. The pressure $P_{0}$ upstream of the two-mass model is parametrically controlled as input data. For all simulations presented below, it is set to $900 \mathrm{~Pa}$, within the range of subglottal pressures commonly measured in the trachea.

The pressure at glottal separation $P_{s 1}$, usually set equal to the atmospheric pressure (Vilain, 2002; Ruty, 2007; Ruty et al., 2007), is equal to $P_{2}$, the pressure estimated in the ventricle, by means of the fluid-flow theory beforementioned. Thus, the simulated laryngeal flow accounts for the pressure recovery owed to the ventricular folds.

The temperature is fixed at $37.2^{\circ}$ and the atmospheric pressure is set to $101.1 \mathrm{kPa}$. Under such thermodynamic conditions,
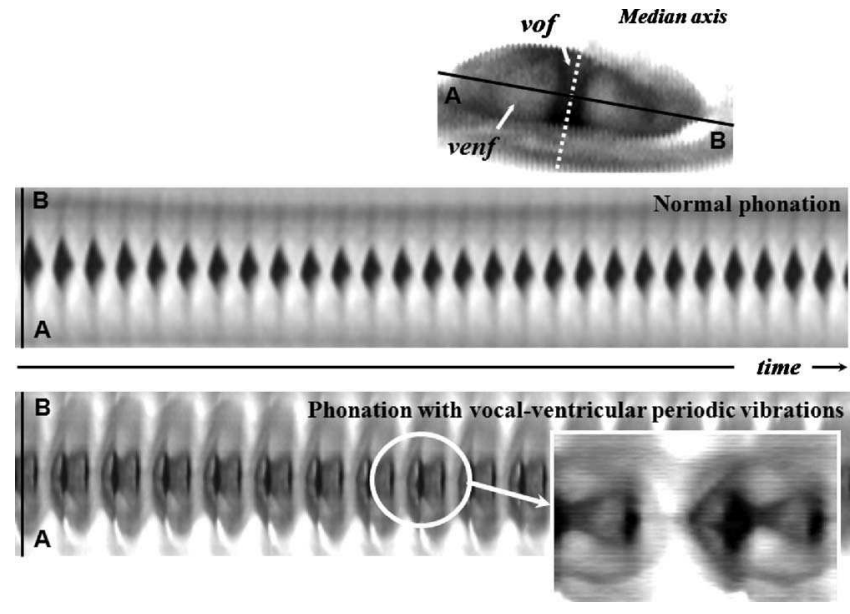

FIG. 5. Comparison between two kymographic views of the selected line $\mathrm{AB}$ on the high-speed image during normal phonation and vocal-ventricular periodic vibrations. Time scaling is different for both analyses. During normal phonation (up), the periodic contact of the vocal folds is illustrated each glottal cycle. During the growly phonation (down), the ventricular fold periodic motion is observed in the foreground, and superimposed to the vocal fold periodic vibration backward.

$$
\begin{aligned}
& \rho=1.13 \mathrm{~kg} \mathrm{~m}^{-3}, \mu=1.85 \times 10^{-5} \mathrm{~kg} \mathrm{~m}^{-1} \mathrm{~s}^{-1}, \\
& c=353.3 \mathrm{~m} \mathrm{~s}^{-1} .
\end{aligned}
$$

where $\rho$ is the air density, $\mu$ the dynamic viscosity, and $c$ the sound celerity.

\section{RESULTS}

\section{A. Physiological description of the co-oscillations \\ 1. Description of ventricular fold vibration}

Figure 5 presents an illustrative kymographic comparison between the normal phonation and the phonation with vocal-ventricular periodic vibrations. Regarding this latter case, different features can be highlighted, in line with previous studies (Fuks et al., 1998; Lindestad et al., 2001; Sakakibara et al., 2001, 2002, 2004; Henrich et al., 2006). The ventricular folds are moving closer each glottal cycle, out of phase with glottal closing. A periodic contact of the ventricular folds is observed for every two glottal cycles. The perceived low pitch corresponds therefore to the fundamental period of the ventricular vibration. It is interesting to note that the singer does not feel the ventricular contact, whereas he mentions proprioceptive feelings during another growly phonation characterized by a strong aryepiglottic constriction.

a. Contact recorded by the EGG measurements during vocal-ventricular vibrations. Figure 6 zooms on five glottal cycles of vocal-ventricular phonation selected from the growly voice recordings. It shows both a kymographic plot of the laryngeal vibratory movement and the EGG and DEGG signals. Figure 7 displays corresponding glottal and ventricular aperture areas together with EGG and DEGG signals. Note that no detection of $\widetilde{A}_{\mathrm{vof}}(t)$ is possible when the ventricular fold motion hides the glottal aperture, which explains the incomplete signal plotted in Fig. 7. In this case, the 

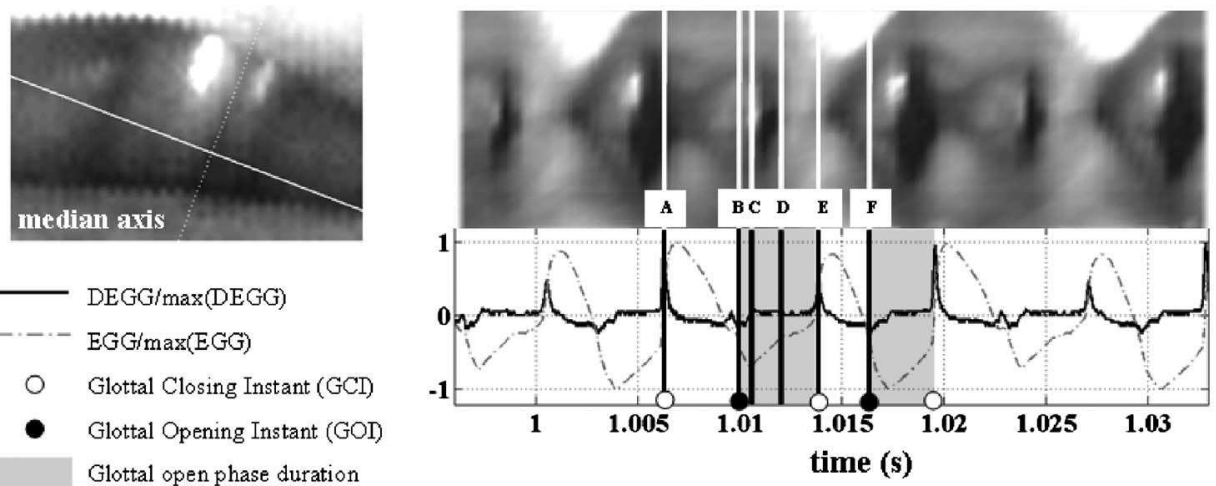

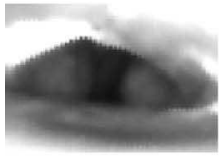

$\Delta$

$\mathrm{DEGG} / \max (\mathrm{DEGG})$

-.-.- EGG/max(EGG)

- Glottal Closing Instant (GCI)

- Glottal Opening Instant (GOI) Glottal open phase duration
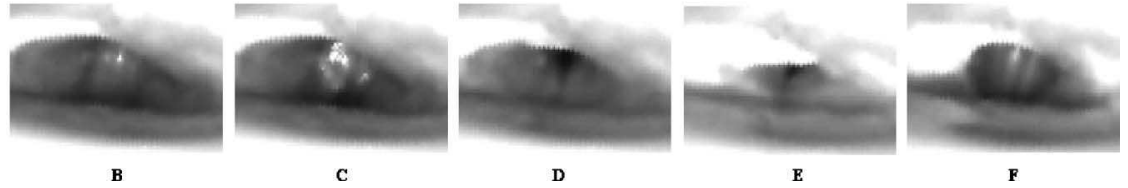

FIG. 6. Zoom on five glottal cycles of a kymographic view, detailing three ventricular fold contacts, along with the synchronized and normalized EGG and DEGG signals. The selected kymographic line is represented on the high-speed image, perpendicular to the median axis. Shot instants are plotted as vertical lines, and the corresponding laryngeal images are given on panels below (A-F).

ventricular contact occurs all along the ventricular fold length in the $z$ direction, so that $\widetilde{A}_{\text {venf }}(t)=0$ at the end of their closing phase.

A periodic alteration of both the EGG and DEGG signals is observed during vocal-ventricular periodic vibrations (see Figs. 6 and 7), illustrating a period-doubling pattern, in agreement with previous observations (Fuks et al., 1998; Lindestad et al., 2001; Sakakibara et al., 2001, 2002, 2004; Henrich et al., 2006). What does this alteration reflect? Selected instants in Figs. 6 and 7 provide further insights into this matter.

- Each time a DEGG positive peak of highest amplitude occurs [see instant A in Fig. 6, instants (a) and (e) in Fig. $7]$, the ventricular folds are coming closer to each other but
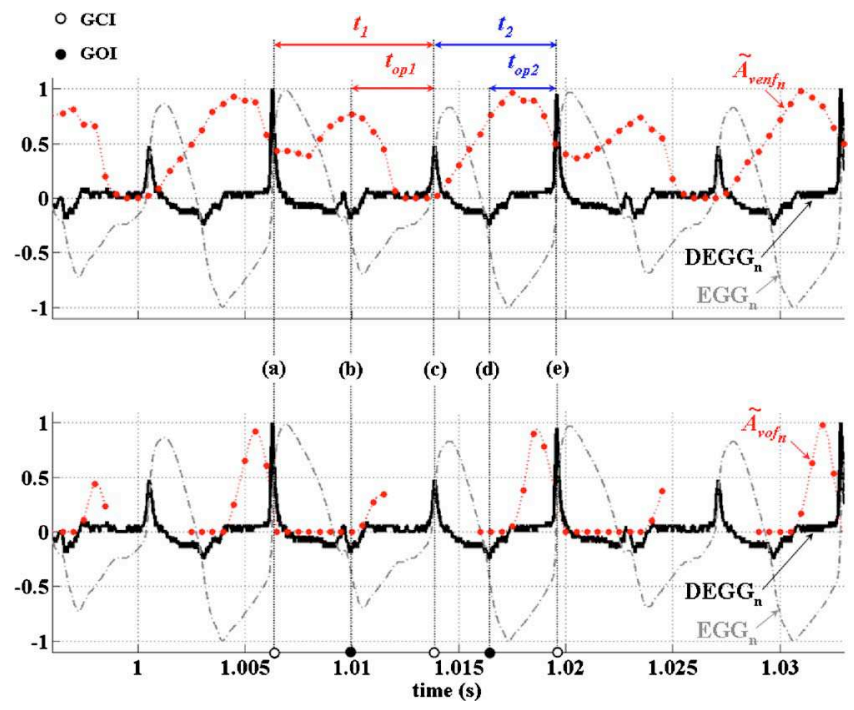

FIG. 7. (Color online) Normalized EGG $\left(\mathrm{EGG}_{n}\right)$ and DEGG $\left(\mathrm{DEGG}_{n}\right)$ signals as a function of time measured during growly phonation, along with synchronized and normalized areas $\widetilde{A}_{\text {venf }_{n}}(t)$ (up) and $\widetilde{A}_{\text {vof }_{n}}(t)$ (down) derived from the high-speed images. Shot instants $(\mathrm{a}-\mathrm{e})$ are plotted as dashed vertical lines. not touching, while the vocal folds are closing. In this case, the amplitude variations on EGG and DEGG signals are due to glottal motions only.

- Each time a DEGG positive peak of smallest amplitude occurs [see instant E in Fig. 6 and instant (c) in Fig. 7], the ventricular folds are already in contact. Data on vocal fold behavior is thus not available. Yet, the observed sudden DEGG amplitude peak is not correlated with any sudden changes in ventricular motion; in fact, the closing of the ventricular folds precedes this instant and is not reflected by a DEGG amplitude peak, although concurrent to a modification of the EGG signal. Therefore, this suggests that the DEGG smallest amplitude peak corresponds only to the closure of the vocal folds. These observations support the thesis that though the EGG may combine information about ventricular and glottal contact areas, the DEGG positive peaks exclusively reflect glottal closing states. Consequently, times $t_{1}$ and $t_{2}$ (see Fig. 7) define two consecutive glottal cycle durations.

- When a DEGG negative peak arises [see instants B and F in Fig. 6, instants (b) and (d) in Fig. 7], the ventricular folds are already apart from each other, whereas the vocal folds are starting their opening phase. Thus, the DEGG negative peaks occur at GOI, in the same way as during normal phonation. Consequently, times $t_{\mathrm{op} 1}$ and $t_{\mathrm{op} 2}$ (see Fig. 7) define two consecutive glottal open phase durations.

b. Correlation between ventricular and glottal motions. The ventricular fold contact follows the glottal opening [time B in Fig. 6 and (b) in Fig. 7]. The ventricular contact starts during the glottal open phase [time B to E in Fig. 6, time (b) to (c) in Fig. 7]. It stops during the closing phase of the following glottal cycle [time E to F in Fig. 6, time (c) to (d) in Fig. 7]. The ventricular opening is initiated at the time of glottal closure. These observations do not depend on the specific kymographic line considered. 


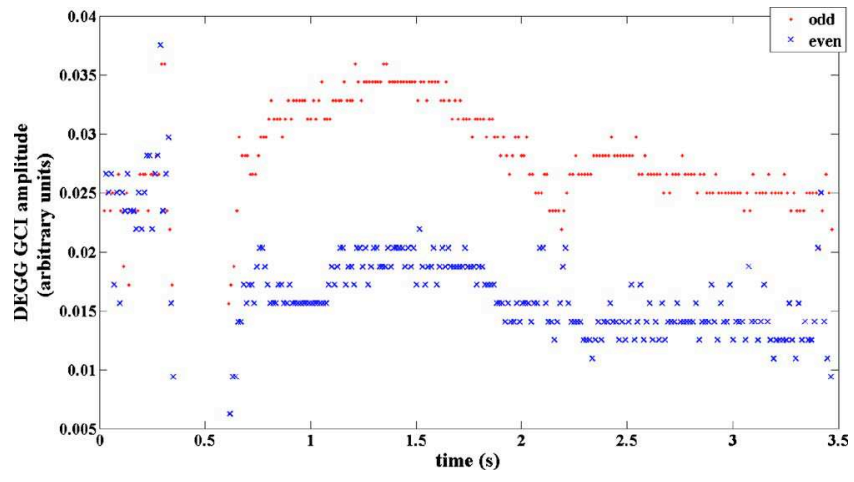

FIG. 8. (Color online) Amplitude of DEGG signal at GCI as a function of time.

\section{Description of vocal fold vibration}

In this part, the impact of the behavior of the ventricular fold on the glottal motion during vocal-ventricular periodic vibrations is quantified.

a. Ventricular impact on glottal speed of contact area. Figure 8 displays the amplitude of the DEGG glottal closing peaks detected on the growl sequence as a function of time. The peaks are numbered in order of appearance: the crosses correspond to even numbers, and the dots to odd numbers (see Fig. 2). Once the period-doubling phenomenon is established, a constant alteration of the amplitude between two consecutive peaks is periodically observed.

As illustrated in Figs. 6 and 7, the peaks of lower amplitude on the DEGG signal (even numbers) occur during a ventricular contact whereas the DEGG peaks of higher amplitude occur at a moment when the ventricular folds have moved apart. As the amplitude of the DEGG signal reflects the speed of vocal fold contact area, the observed periodic alteration of the glottal cycle suggests that the vocal fold speed of contact is noticeably reduced under the influence of the downstream ventricular fold contact.

Note that at the very beginning of the sequence $(t$ $<0.5 \mathrm{~s}$ ), the singer did not succeed in producing the investigated growl but performed a creaky-like sound instead. In this case, the variations of the DEGG signal do not lead to any obvious period-doubling pattern.

$b$. Ventricular impact on the glottal cycle frequencies. Not only is the speed of glottal contact modified by the downstream ventricular vibration, but also the duration of glottal cycle. Figure 9 presents the evolution of glottal cycle frequencies as a function of time. A distinction is made between the glottal cycles, depending on whether the ventricular folds close during the cycle $\left(f_{1}=1 / t_{1}\right)$ or open $\left(f_{2}\right.$ $\left.=1 / t_{2}\right)$. The frequency $2 /\left(t_{1}+t_{2}\right)$ represents twice the frequency of two consecutive glottal cycles. It corresponds to the glottal fundamental frequency, which would have been observed if the ventricular folds were not vibrating. It also corresponds to an octave above the perceived pitch (2. $f_{0}, f_{0}=1 / t_{0}$ being the acoustical fundamental frequency). In normal phonation, $f_{1}=f_{2}=f_{0}$.

During the creaky voice performed at the beginning of the sequence $(t<0.5 \mathrm{~s})$, the fundamental frequency $f_{0}$ is measured at $155 \mathrm{~Hz}$ (D\#3) on average. Once the periodic vocalventricular vibrations have established, it decreases from 80

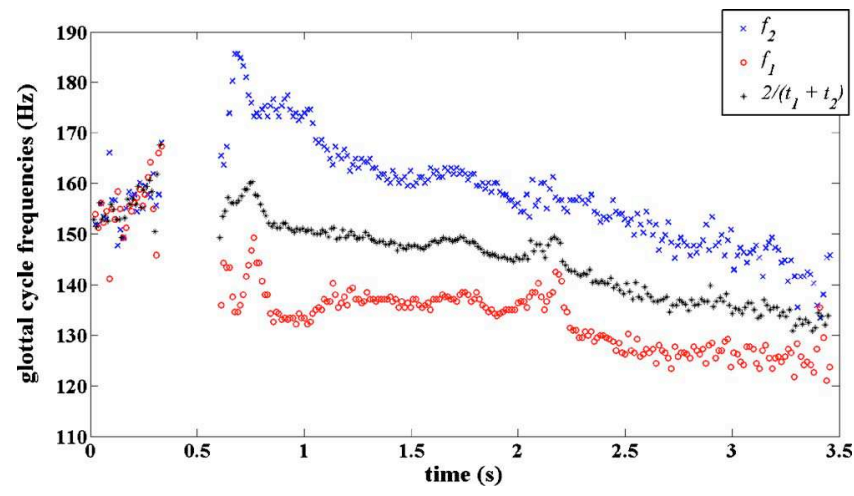

FIG. 9. (Color online) Glottal-cycle frequencies as a function of time.

$\mathrm{Hz}$ (D\#2) to $65 \mathrm{~Hz}(\mathrm{C} 2)$ (mean value $72 \mathrm{~Hz}$ ). During vocalventricular periodic vibrations, two following glottal cycles do not have the same duration $\left(t_{1} \neq t_{2}\right)$ : a glottal cycle with ventricular folds in closing phase is longer than a glottal cycle with a ventricular aperture $\left(t_{1}>t_{2}\right)$, implying a lower glottal cycle frequency $\left(f_{1}<f_{2}\right) . f_{1}$ goes from $149 \mathrm{~Hz}$ to 121 $\mathrm{Hz}$ with a mean value of $133 \mathrm{~Hz}(\mathrm{C} 3) ; f_{2}$ goes from $186 \mathrm{~Hz}$ to $133 \mathrm{~Hz}$ with a mean value of $158 \mathrm{~Hz}(\mathrm{D \# 3})$. The maximal difference between two consecutive glottal cycle frequencies rises to $51 \mathrm{~Hz}$ and fluctuates around a mean value of $25 \mathrm{~Hz}$ in that case. It is interesting to note that the frequencies $f_{0}, f_{1}$ and $f_{2}$ are superimposed at the beginning of the musical sentence, which does not exhibit any period-doubling pattern.

Alteration of the glottal cycle duration during vocalventricular periodic vibrations is confirmed in Fig. 10, which shows the variation in glottal opening durations $\left(t_{\mathrm{op} 1}\right.$ and $\left.t_{\mathrm{op} 2}\right)$ for two successive glottal cycles. It demonstrates that $t_{\mathrm{op} 1}$ is consistently longer that $t_{\mathrm{op} 2}$ during growl; both durations also vary according to fundamental period $t_{0}$ fluctuations. In the studied period-doubling sequence, this lengthening may reach a maximal delay of $2.6 \mathrm{~ms}$ (average value 1.5 $\mathrm{ms})$. The duration relative to fundamental period, i.e., the open quotient $O_{q}$, is also much higher in the case of ventricular fold closing than in case of ventricular fold opening (relative gap of $11 \%$ in average, $23 \%$ at maximum). These features are not observed during normal phonation, nor during the creaky sound produced at the start of the sentence.

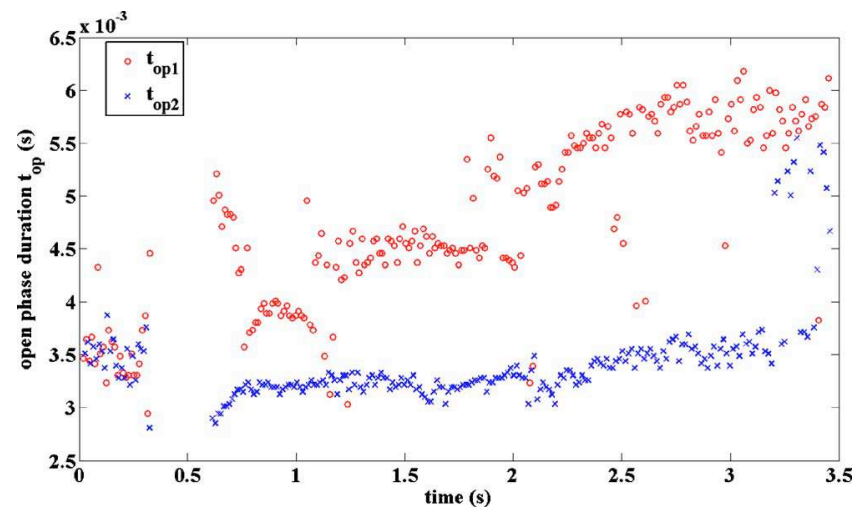

FIG. 10. (Color online) Open phase duration with $\left(t_{\mathrm{op} 1}\right)$ and without $\left(t_{\mathrm{op} 2}\right)$ a ventricular fold contact, as a function of time. 

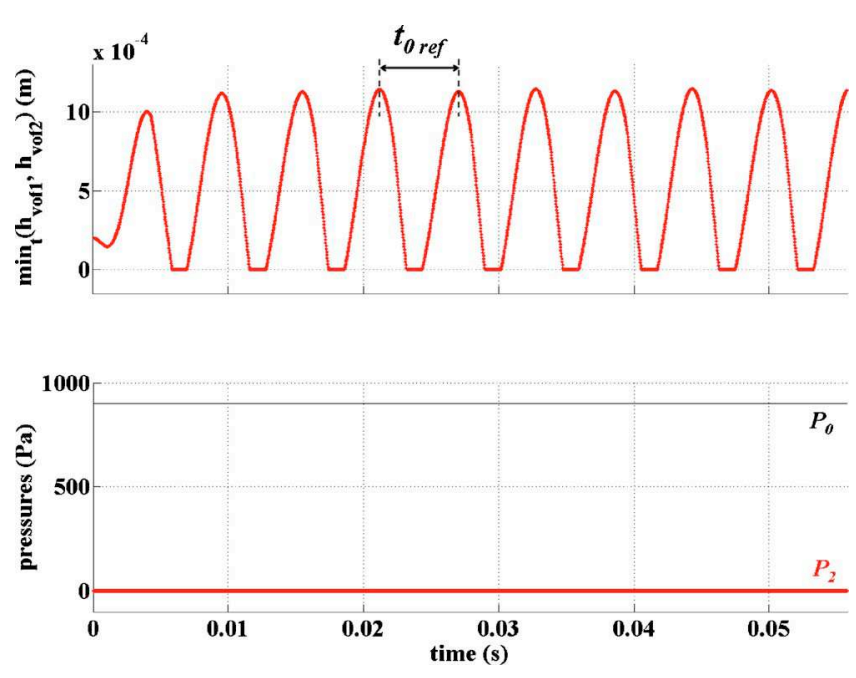

FIG. 11. (Color online) Two-mass simulations of $\min _{t}\left(h_{\mathrm{vof}_{1}}(t), h_{\mathrm{vof}_{2}}(t)\right)$ and $P_{2}(t)$ as a function of time. Configuration of reference with $h_{\text {venf }}(t)$ $=h_{\text {ventricle }}, P_{0}=900 \mathrm{~Pa} .1 / t_{0 \text { ref }}=173 \mathrm{~Hz}$ (mean value). Input (resp. output) data are displayed in thin solid (resp. thick dotted) line.

What could explain these variations in glottal opening durations? The ventricular folds are closing during phase 1 , whereas they are opening and remain completely open during phase 2, as displayed in Fig. 6. This suggests that the duration of the glottal cycle could be extended with a ventricular contact. In Bailly et al. (2008), it is shown that a decreasing ratio $\tilde{h}_{\mathrm{venf}} / \tilde{h}_{\mathrm{vof}}$ can imply a pressure recovery downstream of the glottis, thus reducing the pressure drop and consequently the Bernoulli effect involved in the vocal fold adduction. In light of these previous results, we propose to further explore the hypothesis of a possible aerodynamic interaction between the glottal-flow and the ventricular fold vibration, which could explain the lengthening of the glottal opening duration.

\section{B. Theoretical prediction of the vocal-ventricular interaction}

In this part, the aerodynamic influence of the ventricular fold motion (measured during period-doubling phonation) on the vocal fold self-sustained oscillations is predicted. Figures 11 and 12 present numerical simulations of the glottal behavior obtained using a two-mass model and accounting for the aerodynamic interaction between the vocal folds and the ventricular folds, as described in Sec. II C.

\section{Configuration of reference with an input static ventricular geometry}

Glottal behavior during normal phonation is simulated considering a standard geometry in the input parameters of the two-mass model, characterized by a static ventricular fold aperture such as $h_{\text {venf }(t)}=h_{\text {ventricle }}$.

Figure 11 illustrates this latter configuration. No pressure recovery is predicted in such a case $\left(P_{2}(t)=0\right)$ and the two-mass model of the vocal folds oscillates periodically with a single fundamental frequency $1 / t_{0 \text { ref }}$ (mean value 173 $\mathrm{Hz})$.
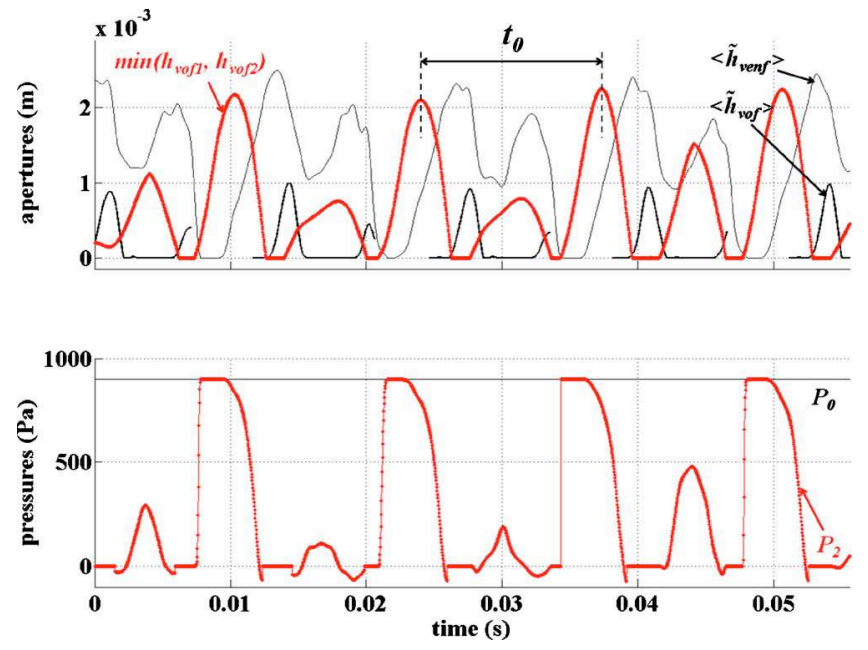

FIG. 12. (Color online) Two-mass simulations of $\min _{t}\left(h_{\mathrm{vof}_{1}}(t), h_{\mathrm{vof}_{2}}(t)\right)$ and $P_{2}(t)$ as a function of time. $h_{\text {venf }}(t)=\left\langle\widetilde{h}_{\text {venf }}\right\rangle(t), P_{0}=900 \mathrm{~Pa} .1 / t_{0}=74 \mathrm{~Hz}$ (mean value). Input (resp. output) data are displayed in thin solid (resp. thick dotted) line.

\section{Simulation of a period-doubling phenomenon at the glottis}

This part presents the glottal behavior and the translaryngeal pressure predicted during vocal-ventricular periodic vibrations, in contrast to the situation shown in Fig. 11.

In this case, the input value of the ventricular aperture $h_{\text {venf }}(t)$ is estimated in agreement with the measurements recorded from explorations of this type of period-doubling phonation in humans, detailed in Sec. II B. Thus, the parameter $h_{\text {venf }}(t)$ follows the variations of the area $\widetilde{A}_{\text {venf }}(t)$ detected on the high-speed images and plotted in Fig. 7 , and is approximated by $\left\langle\tilde{h}_{\text {venf }}\right\rangle(t)$. If coupled to Eqs. (2) and (3), this approximation yields to:

$$
h_{\text {venf }}(t)=\tilde{h}_{\mathrm{venf}_{\mathrm{ref}}} \cdot \widetilde{A}_{\mathrm{venf}_{n}}(t) .
$$

Finally, the input ventricular aperture $h_{\text {venf }}(t)$ estimated by Eq. (8) has been dephased in concordance with the chosen initial glottal aperture $h_{\mathrm{vof}}(t=0)=0.2 \mathrm{~mm}$. Figure 12 presents the predicted glottal aperture $\min _{t}\left(h_{\text {vof1 } 1}, h_{\text {vof } 2}\right)$ and pressure $P_{2}(t)$, with the ventricular motion $h_{\text {venf }}$ measured on high-speed images as an input parameter.

Similarly to Eq. (8), the glottal aperture extracted from the measurements is deduced from the equation below and compared to the simulated M2M oscillations (see Fig. 12):

$$
\left\langle\tilde{h}_{\mathrm{vof}}\right\rangle(t)=\tilde{h}_{\mathrm{vof}_{\mathrm{ref}}} \cdot \tilde{A}_{\mathrm{vof}_{n}}(t) .
$$

Under such conditions, the following three main features can be deduced from the two-mass simulations.

- A large pressure recovery $P_{2}$ is predicted, in contrast to the normal phonation simulation (see bottom panels in Figs. 11 and 12). It even reaches the driving pressure $P_{0}$ each time the ventricular folds are in contact. Therefore, the pressure drop across the vocal folds, $\Delta P_{\text {vof }}$ is affected and the vocal fold self-oscillation is altered.

- An alteration of the glottal aperture amplitude between two consecutive vocal fold oscillations is theoretically pre- 


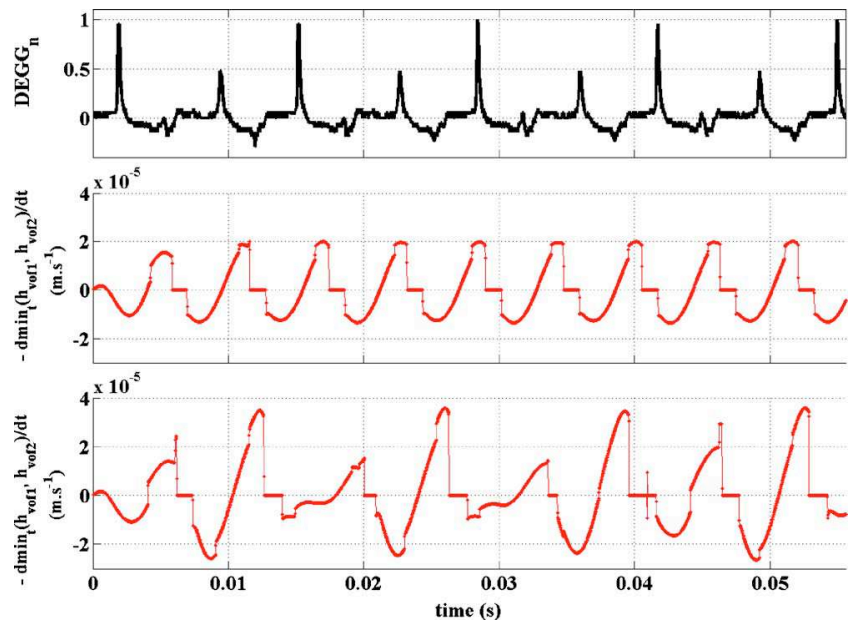

FIG. 13. (Color online) Comparison between the normalized DEGG signal $\mathrm{DEGG}_{n}$ (top), the opposite of the time derivative signal of the glottal aperture simulated by the M2M model $d \min _{t}\left(h_{\mathrm{vof}_{1}}(t), h_{\mathrm{vof}_{2}}(t)\right) / d t$ for $h_{\mathrm{venf}}(t)$ $=h_{\text {ventricle }}($ middle $)$, and for $h_{\text {venf }}(t)=\left\langle\tilde{h}_{\text {venf }}\right\rangle(t)$ (bottom). $P_{0}=900 \mathrm{~Pa}$.

dicted. The rise of pressure $P_{2}(t)$ up to cancellation of the pressure drop $\Delta P_{\text {vof }}$ occurs during the opening phase of the glottal cycle characterized by a maximal amplitude $\min _{t}\left(h_{\mathrm{vof} 1}, h_{\mathrm{vof} 2}\right)$. The ventricular fold contact thus generates an increase in the glottal aperture, according to the simulations. Therefore, the modeling of the aerodynamic vocal-ventricular interaction leads to the simulation of a period-doubling phenomenon at the glottis: a second frequency appears in the vocal fold vibratory pattern, which equals to the fundamental frequency of the ventricular fold oscillation and of the resulting sound, $1 / t_{0}=74 \mathrm{~Hz}$ (see Fig. 12).

- An anti-phase shift between the glottal and the ventricular vibrations is also predicted. Figure 13 compares the delay between the simulated glottal apertures and the measured data during vocal-ventricular periodic vibrations. To this end, DEGG signal variations are compared to the time derivative of the simulated glottal apertures for the standard configuration (as displayed in Fig. 11), and the case with the ventricular motion extracted from the in vivo measurements (as displayed in Fig. 12). The peak detection method allows to define the amplitude maxima of the signal $-d \min _{t}\left(h_{\text {vof }_{1}}(t), h_{\text {vof }_{2}}(t)\right) / d t$, thus reached at simulated GCI. The delay between two consecutive simulated GCI defines the theoretical duration of the corresponding glottal cycle. Two main results are illustrated in Fig. 13 regarding the period-doubling phonation (bottom panel).

- The simulation predicts an alteration of the $-d \min _{t}\left(h_{\mathrm{vof} 1}(t), h_{\mathrm{vof} 2}(t)\right) / d t$ positive peaks amplitude every two glottal cycles; in other words, a noticeable decrease in speed of glottal closing is predicted, in agreement with the measured data.

- The simulation predicts a difference of duration between two consecutive glottal cycles. In the studied case, the discrepancy between two consecutive glottal cycle frequencies varies from $10 \mathrm{~Hz}$ to $46 \mathrm{~Hz}$ according to the simulation (mean value $31 \mathrm{~Hz}$ during the four selected ventricular cycles, if calculated from a simulated GCI peak of highest amplitude), while it varies from $39 \mathrm{~Hz}$ to $42 \mathrm{~Hz}$ according to the DEGG measurements (mean value $41 \mathrm{~Hz}$ ).

These results suggest that the aerodynamic interaction between the vocal folds and the ventricular folds does alter the glottal vibrations in terms of frequency and amplitude in the simulations, which may play an important role in the period-doubling phenomenon. Yet, it is shown in Fig. 13 that an inconsistent phase shift remains between the simulated glottal motions and the measured DEGG signal, and the cycle duration lengthened by the ventricular closure, as observed in phonation (see Fig. 9), is not reproduced under such modeling assumptions.

\section{CONCLUSION}

In this study, the laryngeal dynamics of a specific growly phonation produced by a professional singer using period-doubling as a musical performance is explored. This phonation is perceptually similar to Mongolian Kargyraa, Tibetan voice or Sardinian Bassu singing and involves the vibrations of the ventricular folds. In vivo investigation of this phonation has been carried out using acoustic and electroglottographic measurements, together with high-speed cinematography. A quantification of the laryngeal dynamics is proposed, extracting glottal and ventricular areas from the high-speed images. These data are used as input parameters to a simplified model of phonation accounting for the aerodynamic interaction between the vocal and ventricular folds.

The conclusions that can be drawn from this study are as follows.

- It is observed that, although the EGG signal may combine information about ventricular and glottal contact areas during this specific phonation, the DEGG signal exclusively reflects glottal vibratory behavior.

- A correlation between the vocal fold vibration and the ventricular fold motion is demonstrated.

- As shown in high-speed images, the ventricular folds are moving closer each glottal cycle, out of phase with glottal closing. A contact between the ventricular folds is observed every two glottal cycles. The perceived low pitch corresponds therefore to the fundamental period of the ventricular vibration. The ventricular fold contact starts during the glottal open phase and stops during the closing phase of the following glottal cycle. The ventricular opening corresponds to a glottal closure.

- From the processed in vivo data, it is shown that the ventricular fold closing affects vocal fold movements. Two consecutive glottal cycles do not have the same duration and the duration of the glottal cycle is extended with a ventricular contact. In particular, glottal opening duration is increased when the ventricular folds are closed.

- From the theoretical simulations, it is shown that the alteration of the vocal fold vibration amplitude between two consecutive glottal cycles can be explained by the aerodynamic impact of the ventricular folds. Thus, the simulation exhibits a period-doubling phenomenon at the glottis. In other words, extraction of the ventricular behavior observed during vocal-ventricular periodic vibrations, if com- 
bined to a simplified aerodynamic modeling of the vocalventricular interaction, suffices to predict the perioddoubling phenomenon characteristic of this specific phonation.

- Finally, this work provides quantified in vivo information on vocal fold and ventricular fold interaction recorded during period-doubling phonation on a professional singer, which is of much help for investigating the physical impact of the ventricular folds on the glottal oscillations. Therefore, further study is ongoing to characterize these physiological correlates on a greater number of subjects, and to overcome the main limitations of this study. In particular:

- A better understanding of the delay between the measurements and the predictions of the glottal behavior may be also provided if including an accurate and validated description of the impact stresses occurring during vocal folds collision in the modeling.

- A driven model of the ventricular band variation has been chosen as a first step to determine their aerodynamic impact on the translaryngeal pressure distribution and the glottal vibrations. Yet, exploration of the ventricular motion physical origins will need further modeling, such as a theoretical description of the glottal vibrations mechanical transmission along the laryngeal mucosa.

\section{ACKNOWLEDGMENTS}

This research has been partly supported by a Ph.D. Grant from the French Ministry of Research and Education. The authors gratefully acknowledge Pierre Badin for his very helpful contribution to the contour detection method used to process the data. They also acknowledge Frank Müller, Anna Katharina Licht, Markus Hess and Mal Webb for their precious help during the experimental procedure. They would like also to thank Peter Murphy and Joël Gilbert for their suggestions and participation on this work.

Agarwal, M. (2004). "The false vocal folds and their effect on translaryngeal airflow resistance," Ph.D. thesis, Bowling Green State University, OH.

Agarwal, M., Scherer, R. C., and Hollien, H. (2003). "The false vocal folds: Shape and size in frontal view during phonation based on laminagraphic tracings," J. Voice 17, 97-113.

Alipour, F., Jaiswal, S., and Finnegan, E. (2007). "Aerodynamic and acoustic effects of false folds and epiglottis in excised larynx models," Ann. Otol. Rhinol. Laryngol. 116, 135-144.

Bailly, L. (2009). "Interaction entre cordes vocales et bandes ventriculaires en phonation: Exploration in-vivo, modélisation physique, validation invitro (Interaction between vocal folds and ventricular folds in phonation: In-vivo exploration, physical modelling, in-vitro validation)," Ph.D. thesis, Université du Maine, France.

Bailly, L., Pelorson, X., Henrich, N., and Ruty, N. (2008). "Influence of a constriction in the near field of the vocal folds: Physical modeling and experimental validation," J. Acoust. Soc. Am. 124, 3296-3308.

Finnegan, E. M., and Alipour, F. (2009). "Phonatory effects of supraglottic structures in excised canine larynges," J. Voice 23, 51-61.

Fuks, L., Hammarberg, B., and Sundberg, J. (1998). "A self-sustained vocalventricular phonation mode: Acoustical, aerodynamic and glottographic evidences," KTH Speech, Music and Hearing — Quaterly Progress and Status Report 3, 49-59.

Haji, T., Moir, K., Omori, K., and Isshiki, N. (1992). "Mechanical properties of the vocal fold: Stress-Strain studies," Acta Oto-Laryngol. 112, 559565 .

Henrich, N. (2001). "Etude de la source glottique en voix parlée et chantée: Modélisation et estimation, mesures acoustiques et électroglottographiques, perception (Study of the glottal source in speech and sing- ing: Modelling and estimation, acoustic and electroglottographic measurements, perception)," Ph.D. thesis, Université Paris 6, France.

Henrich, N., d'Alessandro, C., Castellengo, M., and Doval, B. (2004). "On the use of the derivative of electroglottographic signals for characterization of nonpathological phonation," J. Acoust. Soc. Am. 115, 1321-1332. Henrich, N., Lortat-Jacob, B., Castellengo, M., Bailly, L., and Pelorson, X. (2006). "Period-doubling occurrences in singing: The 'bassu' case in traditional Sardinian 'A Tenore' singing," in Proceedings of the Fifth International Conference Voice Physiology and Biomechanics, University of Tokyo, Japan.

Hirano, M., Matsuo, K., Kakita, Y., Kawasaki, H., and Kurita, S. (1983). "Vibratory behavior versus the structure of the vocal fold," Vocal Fold Physiology: Biomechanics, Acoustics and Phonatory Control, edited by I. R. Titze and R. C. Scherer (The Denver Center for the Performing Arts, Denver), pp. 26-40.

Hollien, H., and Colton, R. H. (1969). "Four laminagraphic studies of vocal fold thickness," Folia Phoniatr (Basel) 21, 179-198.

Kitzing, P., and Sonesson, B. (1967). "Shape and shift of the laryngeal ventricle during phonation," Acta Oto-Laryngol. 63, 479-488.

Kucinschi, B. R., Scherer, R. C., DeWitt, K. J., and Ng, T. T. M. (2006). "Flow visualization and acoustic consequences of the air moving through a static model of the human larynx," J. Biomech. Eng. 128, 380-390.

Lindestad, P. A., Blixt, V., Pahlberg-Olson, J., and Hammarberg, B. (2004). "Ventricular fold vibration in voice production: A high-speed imaging study with kymographic, acoustic and perceptual analyses of a voice patient and a vocally healthy subject," Logoped. Phoniatr. Vocol. 29, 162170 .

Lindestad, P. A., Sodersten, M., Merker, B., and Granqvist, S. (2001). "Voice source characteristics in Mongolian 'throat singing' studied with high-speed imaging technique, acoustic spectra, and inverse filtering," $\mathrm{J}$. Voice 15, 78-85.

Lous, N. J. C., Hofmans, G. C. J., Veldhuis, R. N. J., and Hirschberg, A. (1998). "A symmetrical two-mass vocal-fold model coupled to vocal tract and trachea, with application to prosthesis design," Acust. Acta Acust. 84, 1135-1150.

Miller, J. A., Pereira, J. C., and Thomas, D. W. (1988). "Fluid flow through the larynx channel," J. Sound Vib. 121, 277-290.

Nasri, S., Jasleen, J., Gerratt, B. R., Sercarz, J. A., Wenokur, R., and Berke, G. S. (1996). "Ventricular dysphonia: A case of the false vocal fold mucosal travelling wave," Am. J. Otolaryngol. 17, 427-431.

Pelorson, X., Liljencrants, J., and Kroeger, B. (1995). "On the aeroacoustics of voiced sound production," in Proceedings of the 15th International Congress on Acoustics, Trondheim, Norway.

Rothenberg, M. (1992). "A multichannel electroglottograph," J. Voice 6, 36-43.

Ruty, N. (2007). "Modèles d'interactions fluide parois dans le conduit vocal. Applications aux voix et aux pathologies (Fluid walls interactions modelling in the vocal tract. Applications to voice and pathologies)," Ph.D. thesis, Institut National Polytechnique de Grenoble, France.

Ruty, N., Pelorson, X., Van Hirtum, A., Lopez-Arteaga, I., and Hirschberg, A. (2007). "An 'in-vitro' setup to test the relevance and the accuracy of low-order vocal folds models," J. Acoust. Soc. Am. 121, 479-490.

Sakakibara, K. I., Imagawa, H., Niimi, S., and Osaka, N. (2002). "Synthesis of the laryngeal source of throat singing using a $2 \times 2$-mass model," in Proceedings of the International Computer Music Conference, pp. 5-8.

Sakakibara, K. I., Imagawa, H., Niimi, S., and Tayama, N. (2004). "Physiological study of the supraglottal structure," in Proceedings of the International Conference on Voice Physiology and Biomechanics, Marseille, France.

Sakakibara, K. I., Konishi, T., Kondo, K., Murano, E. Z., Kumada, M., Imagawa, H., and Niimi, S. (2001). "Vocal fold and false vocal fold vibrations and synthesis of Khoomei," in Proceedings of the International Computer Music Conference, Havana, Cuba, pp. 135-138.

Serrurier, A., and Badin, P. (2008). "A three-dimensional articulatory model of nasals based on MRI and CT data," J. Acoust. Soc. Am. 123, 23352355.

Shadle, C., Barney, A., and Thomas, D. (1991) "An investigation into the acoustics and aerodynamics of the larynx," Vocal Fold Physiology: Acoustics, Perceptual and Physiological Aspects of Voice Mechanisms, edited by J. Gauffin and B. Hammarberg (Singular Publishing Co., Denver), pp. 73-82.

Švec, J. G., and Schutte, H. K. (1996). "Videokymography: High-speed line scanning of vocal fold vibration," J. Voice 10, 201-205.

Vilain, C. E. (2002). "Contribution à la synthèse de parole par modèles 
physique. Application à l'étude des voix pathologiques (Contribution to speech synthesis by physical modelling. Application to the study of pathological voices)," Ph.D. thesis, Institut National Polytechnique de Grenoble, France.

Von Doersten, P. G., Izdebski, K., Ross, J. C., and Cruz, R. M. (1992). "Ventricular dysphonia: A profile of 40 cases," Laryngoscope 102, 12961301.
Wilson, J. E. (1976). "Variations of the laryngo-pharynx in singing," The NATS bulletin Vol. 31, pp. 20-22.

Zangger Borch, D., Sundberg, J., Lindestad, P. A., and Thalen, M. (2004). "Vocal fold vibration and voice source aperiodicity in 'dist' tones: A study of a timbral ornament in rock singing," Logoped. Phoniatr. Vocol. 29, $147-153$. 